\title{
Internalidade e infalibilidade do intelecto no tratado v.5 das Enéadas de Plotino
}

\section{Robert Brenner Barreto da Silva*}

Resumo: O intento desse breve estudo é argumentar em favor da necessidade de que as Ideias sejam internas ao Intelecto para que se assegure a possibilidade de um empreendimento ontoepistemológico. A infalibilidade é o pressuposto e a meta para poder articular conhecimento e realidade, enquanto que a internalidade é o dispositivo teórico responsável por estabelecer esse amálgama. Através de uma análise pontual dos dois primeiros capítulos do tratado V.5, esperase fundamentar a imprescindibilidade desses recursos para a ontoepistemologia na perspectiva de Plotino.

Palavras-chave: Enéadas. Plotino.Internalidade.Infalibilidade. Intelecto

\section{Internality and infallibility of intellect in v.5 treatise of Plotinus Enneads}

\begin{abstract}
The aim of this short study is to argue in favor of the necessity that Ideas be intern to Intellect in order to ensure the possibility of an ontoepistemological enterprise. The infallibility is the presupposition and the goal to the articulation between knowledge and reality, while internality is the theoretical device responsible to that amalgam. Through a punctual analysis of the first two chapters from V.5 treatise, it hopes to sustain the indispensability of these resources to the ontoepistemology according to the Plotinus understanding.
\end{abstract}

Keywords: Enneads. Plotinus.Internality.Infallibility. Intellect.

\section{Introdução}

No que diz respeito à análise da internalidade e da infalibilidade atribuídas ao Intelecto, os dois primeiros capítulos do tratado V.5, intitulado "Que os inteligíveis não estão fora do Intelecto e sobre o Bem", são os que mais interessam, pois, respectivamente, desenvolvem o argumento de que se os inteligíveis não forem internos ao Intelecto, a cognição intelectual seria falível; e o de que se deve estabelecer a relação de identidade entre Intelecto e inteligíveis a partir da qual se garante a posse da verdade em sentido ontológico, isto é, a base infalível para se pensar em uma filosofia que almeje não se limitar ao ceticismo.

Desta forma, para evitar a dispersão nos muitos temas que o tratado apresenta, a abordagem desse trabalho limita-se aos dois primeiros capítulos. Faz-se uso principalmente dos comentários de O’Meara, Emilsson e Gerson para respaldar e enriquecer a leitura dos passos atinentes à internalidade e à infalibilidade.

\footnotetext{
* Mestre em Filosofia pela Filosofia pela Universidade Federal do Ceará (UFC). E-mail: roberttxplus@ gmail.com.
} 
É de comum acordo que Plotino tem em mente, no tratado V.5, as considerações gnósticas a respeito do cosmos, uma vez que esse texto faz parte de um grupo maior de tratados chamados antignósticos ${ }^{1}$. Entretanto, nem sempre se dá o devido destaque aos oponentes céticos que Plotino visa enfraquecer por meio de suas teses ontoepistemológicas. A infalibilidade buscada por Plotino ao longo de sua argumentação está intimamente relacionada às dificuldades apresentadas pelos céticos no tocante à possibilidade de conhecimento genuíno. Para dar respaldo a essa contextualização, que antecipa a demonstração da necessidade de que a infalibilidade seja considerada como primordial, é importante o comentário de O’Meara:

Retornando à bem-conhecida presença de argumentos céticos no início dos tratados V.5 e V.3, eu tenho sugerido que a abordagem que Plotino adota nesses textos é de considerável significado histórico. Plotino usa argumentos céticos como um método para refutar teorias do conhecimento que se baseiam nas sensopercepções ou na separação entre sujeito e objeto de conhecimento. O ceticismo, portanto, prepara o caminho para a introdução de uma forma de dogmatismo platônico no qual a verdade e o conhecimento estão fundamentados na unidade do sujeito e do objeto do pensamento, uma unidade livre de toda separação através de imagens ou externalidade, um auto-verificado conhecimento imune, como tal, ao ceticismo e capaz de funcionar como um fundamento para outras formas de conhecimento (OMEARA, 2000, p.250-251, tradução nossa ${ }^{2}$ ).

Ainda como introdução, é relevante a observação de Emilsson de que Plotino, logo no primeiro capítulo do tratado em estudo, expõe a cláusula pétrea da sua ontoepistemologia: os objetos do Intelecto não podem ser externos a ele. Ele desenvolve a tese, que é explícita no tratado, segundo a qual, se os objetos do Intelecto não forem internos a ele, não há parâmetros para afirmar que qualquer coisa é justa ou bela, tendo em vista que os princípios inteligíveis lhes seriam alheios:

No capítulo 1 do V.5, Plotino vai além ao argumentar que se os objetos do Intelecto são externos a ele, o Intelecto não reconheceria a justiça e a beleza, por exemplo, porque os princípios do julgamento para justiça e beleza

\footnotetext{
${ }^{1}$ Conforme Soares explica, cf. 2003, p.111, ao apresentar a tese de Harder de que V.5 é parte de um único escrito antignóstico, o tratado V.5 faria parte de um mesmo texto que teria sido subdividido nos tratados III 8[30], V.8 [31], V.5 [32] e II.9[33]. Os títulos são respectivamente: Sobre a natureza, a contemplação e o Uno; 2) acerca da beleza inteligivel; 3) Que os inteligíveis não estão fora do Intelecto e sobre o Bem; 4) contra os gnósticos. Logo, V.5 deve ser compreendido à luz da crítica que Plotino fez aos gnósticos, a qual busca afirmar a correta definição do inteligível sem comprometer o que é produzido a partir dele no cosmos sensível. Plotino, na defesa de um todo harmônico que é proveniente do Uno, busca defender outra configuração metafísica em face da ameaça gnóstica à boa metafísica da tradição.

2 "Returning to the well-known presence of sceptical arguments at the beginning of treatises V 5 and V 3, I have suggested that the approach Plotinus adopts in these texts is of considerable historical significance. Plotinus uses sceptical arguments as a method for refuting theories of knowledge based on sense-perception or which separate the subject from the object of thought. Scepticism thus prepares the way for the introduction of a form of Platonic dogmatism in which truth and knowledge are grounded on a unity of subject and object of thought, a unity free of all separation through mediating images or externality, a self-verifying knowledge immune, as such, to skepticism and capable of functioning as the foundation of other, lower forms of knowledge".
} 
estariam fora do Intelecto (linhas 29-33) (EMILSSON, 1995, p.28, tradução nossa) ${ }^{3}$.

Adiante, lê-se Plotino utilizar o exemplo da imagem de algo que é formado no ouro por um escultor, de modo que o Intelecto seria um simples expectador dessa obra de arte, não o autor. A ilustração objetiva assinalar a diferença entre o conhecimento pleno que se tem sobre si mesmo e o conhecimento exterior que um ente tem a respeito de outro. Emilsson pontua que se essa perspectiva fosse correta, o estatuto epistêmico do nous seria semelhante ao das sensopercepções:

Um pouco depois, (linhas 47-51) ele [Plotino] diz que se os objetos da intelecção estão fora do Intelecto, o Intelecto estaria quase captando algo análogo a representações em ouro feitas por algum escultor ou artífice, e o reconhecimento delas pelo Intelecto seria como a senso-percepção: uma captação de meras representações enquanto as coisas reais (correspondente à Ideia na mente do homem da caverna) escapariam dele (EMILSSON, 1995, p.28, tradução nossa) ${ }^{4}$.

A primeira hipótese que aventou a possibilidade do conhecimento noético ser exterior ao Intelecto baseou-se em uma falsa conjectura, pois, se ele fosse externo, tratar-se-ia apenas de uma imagem e não das coisas como elas são em si mesmas. Com esse entendimento, o estatuto noético seria equivalente ao dos sensíveis. Mas essa premissa causa embaraço em toda a ontoepistemologia, inclusive para a organização cognitiva dos sensíveis, haja vista a alegada ausência de princípios que ordenem as experiências daquele que percebe como sendo de tais e tais tipos. Ora, o máximo que poderíamos pensar seria em discursos sobre qualidades secundárias atribuídas às percepções, mas jamais chegar ao conceito que tornaria intersubjetiva a compreensão das coisas. Leia-se o comentário:

E se o Intelecto captasse esse tipo de representações das coisas reais, ele [Plotino] pergunta, como uma coisa apreendida pelo Intelecto seria justiça e outra beleza? O ponto dessas passagens - um ponto que Plotino explicitamente faz - é que a menos que as Ideias sejam realmente internas ao Intelecto, elas (e por conseguinte tudo o mais) seria desconhecido. Os padrões mais elevados da verdade para um Platonista são certamente as Ideias, se elas em si mesmas estão fora da mente divina, e a mente divina tem apenas representações dela, o seu conhecimento seria de segunda-mão. A representação da justiça que a mente divina teria seria algo como a qualidade

\footnotetext{
3 "In chapter 1 of V. 5 Plotinus argues further that if the objects of intellect are external to it, the intellect would not recognize justice and beauty, for instance, because the principles of judgment for justice and beauty would be outside the intellect (lines 29-33)".

4 "A little later (lines 47-51) he says that if the objects of intellection are outside the intellect, the intellect would almost grasp something analogous to representations in gold made by some sculptor or engraver, and the intellect's awareness of them would be like sense-perception: a grasp of mere representations while the real thing (corresponding to the idea in the craftsman's mind) would escape it".
} 
de ser justo, mas não a justiça em si mesma, apenas uma mera representação dela (EMILSSON, 1995, p.28, tradução nossa) ${ }^{5}$.

\title{
Análise dos primeiros capítulos do tratado V.5[32]
}

Ao partirmos para o próprio texto de Plotino, é possível depreender da argumentação do filósofo a vinculação que ele estabelece entre a falibilidade ou infalibilidade do Intelecto com a possibilidade de existir conhecimento verdadeiro ou não. Ou seja, para ele, a relação do Intelecto com os inteligíveis principia toda a ontoepistemologia, de modo que o paradigma da internalidade é afirmado sob pena da pesquisa filosófica se tornar destituída de sentido, uma vez que a razão se tornaria prisioneira de uma dúvida perene sobre a validade de seu conhecimento:

\begin{abstract}
Mas a maior objeção é essa: se, de fato, alguém afirmar que esses inteligíveis são totalmente externos ao Intelecto, e então alegarem que o Intelecto os contempla dessa maneira, segue-se necessariamente que ele não possui a verdade dessas coisas, e que ele é enganado em tudo que contempla, pois os inteligíveis seriam a verdadeira realidade. O Intelecto os contemplará sem, contudo, tê-los. Ao contrário, ele se enganará com as representações refletidas nessa espécie de cognição. Logo, não possuirá a verdadeira realidade, de outro modo, será enganado com as representações da verdade, terá falsidades e nada verdadeiro. Se, então, ele souber que tem falsidades, irá concordar que não tem parte alguma com a verdade. Mas, se ele é ignorante quanto a isso também, e pensa que tem a verdade quando não as tem, a falsidade que é gerada nele é dupla, e tal falsidade irá separá-lo consideravelmente da verdade (V.5[32], 1,50-60, tradução nossa ${ }^{6}$ ).
\end{abstract}

Assim, a via do primeiro capítulo é a de associar Intelecto e inteligíveis com o objetivo de assegurar a infalibilidade do nous como condição sine qua non para a existência de qualquer outro tipo conhecimento. Por isso, não é sem razão admitir que Plotino esteja, não apenas nesse tratado, mas em outros de caráter especialmente ontoepistemológico - como é o caso do V.3 (Sobre a hipóstase cognitiva)-, preocupado com as objeções céticas endereçadas ao autoconhecimento. Se não for pressuposto que há uma dimensão na qual o ser e o pensar sejam os mesmos, todo ato cognitivo estaria sujeito a ser valorado sem distinções. Isto é, independente do mérito ou da pretensão de rigor com os quais determinado projeto cognoscitivo se propõe a conhecer. Desta forma, todas as tentativas de conhecer estariam igualmente suscetíveis à falibilidade. Não

\footnotetext{
5 "And if the intellect grasped such representations of the real thing, he asks, why should one thing that the intellect grasps be justice and another beauty? The point of these passages - a point Plotinus himself explicitly makes — is that unless the Ideas are really internal to the intellect, they (and thereby everything else) will be unknowable. The ultimate standards of truth for a Platonist are of course the Ideas; if they themselves are outside the divine mind and the divine mind has only representations of them, its knowledge will be second hand; the representation of justice that the divine mind had access to would be something that may have the quality of being just, but it would not be justice itself, only a mere impression of it".

${ }^{6}$ Os textos do V.5 são baseados na tradução inglesa de GERSON, 2013.
} 
haveria critérios para dizer que projetos A ou B são melhores que X ou Y pela ausência de referenciais objetivos em função dos quais o juízo se tornaria viável.

Enquanto que a infalibilidade, por outro lado, presumiria a possibilidade de se saber que o que se sabe pode ser falso, porque há algo verdadeiro que orienta a pesquisa. Pode-se, então, avançar por participação no que é verdadeiro, ao menos pela via negativa do conhecimento, isto é, por eliminação daquilo que não pode ser. Essa é inclusive a marca do discurso apofático tão empregado por Plotino para tratar, particularmente, do Uno. Ao utilizar esse expediente, não diz-se propriamente a definição de determinado conceito, mas infere-se o que ele não é. Se não consigo predicar positivamente o Uno, é possível dizer que ele é inefável. Contudo, o acordo de que há uma dimensão epistêmica infalível traz implicações significativas para a filosofia, pois ela parte de uma certeza sobre a qual pode trilhar seus itinerários teóricos, ainda que profundamente limitados.

O único caminho plausível para afirmar a infalibilidade desse constructo teórico postulado por Plotino é, por conseguinte, afirmar que os inteligíveis são internos ao Intelecto. Gerson pondera a respeito desses empecilhos na esteira da consideração de que o filósofo em análise busca refutar os céticos, pois avalia que tais objeções céticas, se tomadas em sua radicalidade teórica, podem esvaziar a própria atividade filosófica de sua razão de ser:

\footnotetext{
Plotino, como Sexto, acredita que a infalibilidade é uma propriedade do conhecimento. Mais precisamente, ele acredita que é uma propriedade da mais elavada forma de cognição, o ne plus ultra da cognição, a noēsis do intelecto. Uma vez que ele tenha estabelecido que o conhecimento é infalível, que é possível e que realmente existe, Plotino prosseguirá argumentando em outros tratados que, para várias formas de cognição de natureza corpórea, a existência de conhecimento infalível permanece como um baluarte contra a afirmação cética arrebatadora de que, sem tal conhecimento, a suspensão total da crença é o único curso racional de ação. No presente tratado, admitir que os inteligíveis sejam externos ao Intelecto implica que nada lhe é autoevidente e que, portanto, ele não tem conhecimento. Se o Intelecto, ou pelo menos algum intelecto, é desprovido de conhecimento, então não apenas o conhecimento é impossível para os seres humanos encarnados, mas a razão e a filosofia em si mesmas são tornadas impotentes (GERSON, 2013, p.66-67, tradução $\left.\operatorname{nossa}^{7}\right)$.
}

\footnotetext{
7 "Plotinus, like Sextus, believes that infallibility is a property of knowledge. More precisely, he believes that it is a property of the highest form of cognition, the ne plus ultra of cognition, the noessis of Intellect. Once he has established that infallible knowledge is possible and that it actually exists, Plotinus will go on to argue in other treatises that, for various forms of embodied cognition, the existence of infallible knowledge stands as a bulwark against the sweeping skeptical claim that without such knowledge, total suspension of belief is the only rational course of action. In the present treatise, to grant the claim that intelligibles are external to Intellect is thereby to grant that nothing is self-evident to Intellect and that therefore it has no knowledge. If Intellect, or at least some intellect, is bereft of knowledge, then not only is knowledge impossible for embodied human beings, but reason and philosophy itself are rendered impotent".
} 
Após assegurar a infalibilidade do Intelecto, Plotino discorre sobre a relação de identidade que tal conceito mantém com os inteligíveis. É importante que eles sejam indissociáveis para que haja fundamentos ontoepistemológicos sólidos. Tal conclusão decorre naturalmente da premissa de que os inteligíveis são internos ao Intelecto. Se essa identidade não for reconhecida, como foi dito, restaria apenas a suspensão do juízo, para além da qual não teríamos mais que qualquer tipo de arbitrariedade. Isto é, a atititude intelectualmente honesta seria inexoravelmente a de que não podemos dizer com segurança se sabemos alguma coisa. Leia-se o trecho emblemático do tratado V.5 para a confirmação da identidade noética:

Então, a verdade real também não é estar em harmonia com outra coisa, mas consigo mesma, e não expressa nada além de si mesma, mas o que exprime é. E é também o que exprime. Quem, então, poderia refutar isso? E de onde alguém tiraria a refutação? Pois a refutação alegada contaria com a coisa idêntica dita antes, e mesmo que você fornecesse outro dado, ele seria trazido de acordo com o que foi dito originalmente e estaria em unidade com isso, pois você não pode encontrar nada mais verdadeiro que a verdade (V.5[32]2,18-24).

Como adendo ao ponto principal desse trecho relativo à identidade entre Intelecto e Ideias, auxilia na compreensão do texto o comentário mais abrangente de Gerson com respeito ao conteúdo desse segundo capítulo:

\begin{abstract}
A verdade no sentido primário não é encontrada em alguma correspondência entre os conteúdos do pensamento e a realidade. Eu assumo que isso é o que a metáfora de "estar em harmonia com" (sumphonosa) quer transmitir. O que, então, é "estar em harmonia consigo mesmo?" Talvez a harmonia consista na consciência que o Intelecto tem de que os inteligíveis são reais e presentes nele (GERSON, 2013, p.106-107, tradução nossa ${ }^{8}$ ).
\end{abstract}

Logo, a via do segundo capítulo é confirmar a identidade entre Intelecto e Ideias, não como mera correspondência entre duas partes análogas, mas como consciência reflexiva de que ele é aquilo que pensa. Assim, internalidade e autoconhecimento caminham, do ponto de vista teórico, juntos. Por sua vez, se é pertinente o entrelaçamento do Intelecto com os inteligíveis, pode-se afirmar que o conhecimento noético é infalível, pois não haveria nada a respeito do que o Intelecto seria ignorante.

Ora, o Intelecto significa tudo o que há e ao mesmo tempo ele se define essencialmente pelo pensamento. A conjunção desses predicados implica uma resposta

\footnotetext{
8 "Truth in the primary sense is not found in some correspondence between the contents of Intellect's thinking and reality. I assume that this is what the metaphor of "being in harmony with" (sumphonousa) conveys. What then is "being in harmony with itself"? Perhaps the harmony consists in the awareness by Intellect of the presence of intelligibles in it and the actual presence".
} 
a seguinte pergunta retórica: como o Intelecto conheceria tudo que é inteligível sem conhecer a si mesmo? Essa dupla determinação relativa ao ser e ao conhecer parece circular, mas é o que Plotino estabelece como axioma para pensar a validade do conhecimento.

Ao partir do Intelecto, o método cético teria que produzir contradições internas ao pensamento noético, mas Plotino julga ter sustentado a inteira coerência da relação de identidade entre intelecto e inteligíveis, não tendo deixado qualquer margem para a impugnação do autoconhecimento do nous. Para o autor, é perfeitamente lógico que quem pensa, pensa em algo. Não seria diferente - guardadas as devidas proporções epistêmicas - com o Intelecto. O nous tem como conteúdo de seu pensamento os inteligíveis, isto é, a si mesmo. Por isso, autoconhecimento, internalidade e identidade estão em plena sintonia no texto de Plotino.

Pode-se falar, nessa perspectiva teórica, que as normas lógicas exercitadas pela razão humana provêm do fato de que o Intelecto engendra, enquanto constituinte metafísico do ser e do pensamento, esses princípios intelectivos no cosmos dentro do qual o homem está inserido. Em outras palavras, a partir do momento que a metafísica ganha caráter assertivo quanto a sua natureza intelectual, o pensamento racional sai da condição de mera especulação para fazer parte daquilo que é dotado de inteligibilidade.

Por homologia, a linguagem pode indagar sobre os paradigmas que orientam seu discurso, ainda que esses a extrapolem e introduzam o domínio da supradiscursividade. Isto é, a razão, ainda que não tenha conhecimento total, conhecerá que é limitada e que é condicionada por algo que a transcende. Assim, os referenciais teóricos que levariam a desconfiança podem ser redirecionados para uma atitude teorético-contemplativa a partir da qual a atividade da filosofia surge.

\section{Considerações Finais}

A internalidade nada mais é do que o reconhecimento de que há uma dimensão na qual ser e pensar são o mesmo, de modo que tudo que é pensado nesse nível coincide com aquilo que é. Por conseguinte, concebe-se um tipo de conhecimento que é infalível e que, portanto, possibilita uma postura filosófica otimista quanto às competências cognitivas, na medida em que pressupõe existir verdade e não apenas engano. Nesse 
sentido, a infalibilidade se apresenta como alternativa teórica à perplexidade e a suspensão de juízo de origem cética.

As profundas limitações da razão não são eliminadas ou ignoradas, mas põe-se um horizonte de pesquisa, que no primeiro momento é o inteligível, mas que, ao longo da filosofia de Plotino, mostrar-se-á ser a experiência mística com o Uno. A dialética que estimula o filósofo a ir além das percepções só se sustenta sob o pressuposto de que de fato há algo a ser buscado. Se tudo está sujeito ao devir, a tarefa da epistemologia parece se tornar inútil. Doravante a certeza da infalibilidade, o empreendimento ontoepistemológico continua sendo válido.

Para o momento, o texto "Que os inteligíveis não estão fora do Intelecto" traz, conforme foi argumentado, a necessidade da internalidade e da infalibilidade como pressupostos indispensáveis para qualquer intenção de se construir um edifício ontoepistemológico. Se essas ideias forem contrariadas, parece restar somente a dúvida ad infinitum sobre, em primeiro lugar, a nossa competência cognitiva e, em segundo lugar, sobre a própria realidade que supomos conhecer de alguma maneira.

\section{Referências}

EMILSSON, E. K. Plotinus on the Objects of Thought. Archiv für Geschichte der Philosophie 77.1, 1995, p. 21-41. https://doi.org/10.1515/agph.1995.77.1.21

GERSON, Lloyd. Plotinus Ennead V.5: That the Intelligibles are not External to the Intellect, and on the Good. Translation with an Introduction and Commentary. Parmenides Publishing. Chicago, IL. 2013.

OMEARA, Dominic. Scepticism and Ineffability in Plotinus. Phronesis, vol.45, No.3 (Aug.,2000), pp.240-251. https://doi.org/10.1163/156852800510207

SOARES, L. G. E. C. Plotino, Acerca da Beleza Inteligível (Enéada V, 8 [31]) Introdução, tradução e notas. Kriterion (UFMG, Impresso), Belo Horizonte V.XLIV n ${ }^{\circ}$ 107. p.110-135, 2003. https://doi.org/10.1590/S0100-512X2003000100009

Data de registro: 05/03/2019

Data de aceite: 11/09/2019 